\title{
Medication regimen complexity and medication adherence in elderly patients with chronic kidney disease
}

\author{
Krystina PARKER, ${ }^{1,2}$ (1) Ingrid BULL-ENGELSTAD, ${ }^{3}$ Willy AASEB $\varnothing,{ }^{1}$ Nanna VON DER LIPPE, ${ }^{2,4}$ \\ Morten REIER-NILSEN, ${ }^{3}$ Ingrid OS, ${ }^{2,4}$ Knut STAVEM ${ }^{2,5,6}$ \\ Departments of ${ }^{1}$ Nephrology, and ${ }^{5}$ Pulmonary Medicine, Medical Division, Akershus University Hospital, \\ Lørenskog, ${ }^{2}$ Faculty of Medicine, University of Oslo, Institute of Clinical Medicine, Oslo, ${ }^{4}$ Department of \\ Nephrology, Medical Division, Oslo University Hospital Ullevål, Oslo, ${ }^{3}$ Department of Nephrology, Medical \\ Division, Vestre Viken HF, Drammen Hospital, Drammen and ${ }^{6} H \varnothing K H$, Department of Health Services \\ Research, Akershus University Hospital, Lørenskog, Norway
}

\begin{abstract}
Introduction: Elderly patients with chronic kidney disease (CKD) stage 5 with or without dialysis treatment usually have concomitant comorbidities, which often result in multiple pharmacological therapies. This study aimed to identify factors associated with medication complexity and medication adherence, as well as the association between medication complexity and medication adherence, in elderly patients with CKD.

Methods: This prospective study involved elderly patients with CKD stage 5 (estimated glomerular filtration rate $<15 \mathrm{ml} / \mathrm{min} / 1.73 \mathrm{~m}^{2}$ ) recruited from three Norwegian hospitals. Most of the patients were receiving either hemodialysis or peritoneal dialysis. We used the Medication Regimen Complexity Index $(\mathrm{MRCl})$ to assess the complexity of medication regimens, and the eight-item Morisky Medication Adherence Scale (MMAS-8) to assess medication adherence. Factors associated with the $\mathrm{MRCl}$ and MMAS-8 score were determined using either multivariable linear or ordinal logistic regression analysis.

Findings: In total, 157 patients aged $76 \pm 7.2$ years (mean \pm SD) were included in the analysis. Their overall $\mathrm{MRCl}$ score was $22.8 \pm 7.7$. In multivariable linear regression analyses, female sex $(P=0.044)$, Charlson Comorbidity Index of 4 or $5(P=0.029)$ and using several categories of phosphate binders $(P<0.001$ to 0.04$)$ were associated with the $\mathrm{MRCl}$. Moderate or high adherence (MMAS- 8 score $\geq 6$ ) was demonstrated by $83 \%$ of the patients. The multivariable logistic regression analyses found no association of medication complexity, age or other variables with medication adherence as assessed using the MMAS-8.

Discussion: Female sex, comorbidity and use of phosphate binders were associated with morecomplex medication regimens in this population. No association was found between medication regimen complexity, phosphate binders or age and medication adherence. These findings are based
\end{abstract}

Correspondence to: Krystina Parker, Department of Nephrology, Akershus University Hospital, 1478 Lørenskog, Norway, E-mail: krystina.parker@medisin.uio.no

Use of the Morisky Medication Adherence Scale (@ MMAS) is protected by U.S. copyright laws. Permission for use is required. A license agreement is available from Donald E. Morisky at dmorisky@gmail.com or MMAS Research LLC 14725 NE 20th ST. Bellevue WA 98007.

Conflict of interest statement: No author has a conflict of interest to report.

Disclosure of grants or other funding: No grants or other specific funding received. 
on a homogeneous elderly group, and so future studies should test if they can be generalized to patients of all ages with CKD.

Key words: medication, complexity, adherence, elderly, chronic kidney disease

\section{INTRODUCTION}

Chronic kidney disease (CKD) is common in the elderly. ${ }^{1,2}$ Patients in the advanced stage of CKD have an estimated glomerular filtration rate (eGFR) below $15 \mathrm{ml} / \mathrm{min} / 1.73 \mathrm{~m}^{2}$ (CKD stage 5), and they are treated either conservatively or with dialysis or kidney transplantation. Elderly patients with CKD often have multiple comorbidities and may suffer from reduced sleep quality, pain, cognitive impairment, and frailty. This means that such patients often require multiple pharmacological therapies, which represents a challenge to both patients and physicians due to the complexity of the medications, potential adverse side effects and poor medication adherence. ${ }^{3-5}$

Variations in the dosages, frequencies, and administration instructions of medications contribute to the complexity of a medication regimen. A standardized definition of the complexity of medication regimen is lacking, but recently a standardized and validated tool called the Medication Regimen Complexity Index (MRCI) has been developed to quantify the complexity of any medication regimen. ${ }^{6}$ There are several reports on the MRCI being associated with rehospitalization, mortality, and medication adherence. ${ }^{7-11}$ However, few studies have applied this scoring system to CKD patients, and one of them reported an association between the MRCI and medication adherence. ${ }^{12,13}$

Medication adherence is defined as the extent to which a patient's medication-taking matches the prescribed regimen. ${ }^{10}$ Nonadherence with medication is common both in predialysis and dialysis patients, and it is associated with increased morbidity and mortality. ${ }^{10,14,15}$ The reported prevalence of medication non-adherence has ranged from 13\% to 99\% in hemodialysis (HD) patients and from $4 \%$ to $85 \%$ in peritoneal dialysis (PD) patients. ${ }^{16-19}$ Medication adherences is commonly assessed using pill counts, electronic monitoring devices, biochemical measures or self-reported questionnaires. Medication adherence in patients with CKD is associated with age, sex, education, quality of life, anxiety and depression, as well as medication-related factors such as pill burden, use of phosphate binders and lifelong treatment. 3,18-20

Several previous studies have investigated medication adherence in CKD patients across all age groups, but none has focused on the elderly alone. ${ }^{16,18}$ Medication-related factors such as pill burden, number of phosphate binders, and medication complexity have been found to influence medication non-adherence. However, only a few studies have assessed the association between medication complexity and medication adherence using standardized tools for assessing medication complexity. ${ }^{8}$ To the best of our knowledge, studies focusing on understanding medication regimen complexity and its association with medication adherence in elderly patients are lacking.

The aims of the present study were therefore to identify the factors associated with medication complexity and self-reported medication adherence in elderly patients with CKD stage 5, as well as the association between medication complexity and medication adherence.

\section{METHODS}

\section{Design and population}

This was an investigator-initiated study involving three Norwegian hospitals: Akershus University Hospital, Oslo University Hospital, Ullevål and Vestre Viken Hospital Trust Drammen Hospital. We included patients aged $\geq 65$ years in predialytic CKD stage 5 (eGFR $<15 \mathrm{ml} / \mathrm{min} / 1.73 \mathrm{~m}^{2}$ ) and who were receiving HD or PD. All patients receiving dialysis were asked to participate during a scheduled dialysis session, and predialytic patients were recruited consecutively during their scheduled ambulatory clinic visits. The inclusion period was from June 2015 until January 2017. We excluded patients with severe hearing loss or visual impairment, a dementia diagnosis or Mini Mental State ExaminationNorwegian Revision (MMSE-NR) score $<23$, or perceived unsatisfactory knowledge of the Norwegian language.

\section{Data collection and variables}

After consenting to participate, the patients were invited to a semi-structured interview that focused mainly on patients' current use of prescribed and over-the-counter medications, administration of medications and side effects. All interviews were conducted by one investigator (K.P.). The interview consisted of closed questions with additional open follow-up questions. During each 
interview, the investigator verified the patient's medical history, comorbidities, and current medications. The cognitive function of each patient was evaluated by them completing the MMSE-NR questionnaire during the interview. The interviews were not recorded or transcribed verbatim.

After completing the interview, each participant was given an envelope with questionnaires to be answered at home and returned to the investigator using postageprepaid envelopes. Non-respondents received one telephone reminder.

We assessed comorbidities using the Charlson Comorbidity Index (CCI), which consists of 19 weighted comorbidities that are summed to give a total score. ${ }^{21}$ The CCI has previously been validated in dialysis patients. ${ }^{22}$

\section{Medication regimen complexity and pill burden}

We registered the number of medications defined as the number of different medications each patient took at home including over-the-counter medications and asneeded medications.

The MRCI was used to assess medication complexity. This tool has 65 items and was designed to quantify the complexity of prescribed medication regimens. ${ }^{6}$ It consists of three sections: A (dosage forms), B (dosing frequency) and $C$ (additional direction), with 32, 23, and 10 items, respectively. We coded each medication item according to the weighted scoring system and summed the aggregated score to a total score for the medication complexity. ${ }^{6}$ There is no maximum score as the total score increases continuously when adding dosage forms, dosing frequency or additional directions. Studies using the MRCI have found scores ranging from 8.5 to 28.3 in elderly patients and patients with CKD. ${ }^{12,13,23,24}$ The daily total pill burden was defined as the total number of all tablets or capsules taken by the patients on a daily basis, including as-needed and over-the-counter medications.

\section{Medication adherence}

Medication adherence was registered using a Norwegian version of the self-reported eight-item Morisky Medication Adherence Scale (MMAS-8), which is a structured questionnaire with documented reliability and validity in various patient groups. ${ }^{25-28}$ This questionnaire has seven items with "yes" or "no" answers and one item scored on an ordinal scale from 0 to 4 . Items 5 and 8 of the questionnaire were transformed in accordance with the scoring algorithm, and all items were combined into a total score, which graded adherence on a scale from 0 to 8 . Adherence was interpreted as low $(<6)$, moderate ( 6 to $<8)$ or high $(=8){ }^{26}$

\section{Ethical considerations}

The Regional Committee for Research Ethics reviewed and approved the study (REK no.2014/1255). The study was conducted in accordance with the Helsinki declaration. Both oral and written information about the study was provided to the patients, and a signed informedconsent form was required for enrolment in the study.

\section{Statistical analysis}

Descriptive data are reported as mean $\pm \mathrm{SD}$, median (range) or number (\%) values, as appropriate. In further analyses, the PD and HD patient groups were combined into a single group (dialysis) due to the small number of patients receiving PD. MMSE-NR scores were dichotomized using a criterion for normal cognitive function of $\geq 28$. ${ }^{29}$ The CCI values were divided into three categories: 2 or 3, 4 or 5, and $>5$. Phosphate binders were divided into five categories: none and the four quartiles of phosphate binders use (in grams per day).

We used multivariable linear regression analysis to identify factors associated with medication complexity, with the MRCI as the dependent variable. Explanatory variables were selected for this regression model based on the literature, perceived clinical relevance and the use of a directed acyclic graph. Age, sex, MMSE-NR score, CCI, CKD treatment and use of phosphate binders were included as independent variables in the model. Due to overlapping concepts and hence close associations between the total pill count, the number of different medications and use of phosphate binders, we chose to include only the use of phosphate binders in the regression analyses.

We used multivariable ordinal logistic regression analysis to assess factors associated with medication adherence, with ordinal categories of MMAS- 8 scores as the dependent variable: low $(<6)$, moderate $(6$ to $<8)$ and high $(=8)$. Independent variables were selected for the model in a similar way to that described above. We included age, education, CCI, use of phosphate binders, CKD treatment, the MRCI, and medication administration support (yes vs. no) in the model. The proportional odds assumption was tested using the Brant test, and found to be satisfactory. ${ }^{30}$

The result from an ordinal logistic regression analysis can be interpreted as the probability of being in groups greater than $k$ vs. being in groups less than or equal to $k$, 
where $k$ is the level of the response variable. This probability is expressed as an odds ratio, and is constant across all levels of the dependent variable. Therefore, in the present analysis the proportional odds ratio represents the odds of moderate/high adherence (MMAS-8 score $\geq 6$ ) vs. low adherence (MMAS- 8 score $<6$ ) and the odds of high adherence (MMAS-8 score $=8$ ) vs. moderate/low adherence (MMAS-8 score < 8).

A 5\% significance threshold was applied for two-tailed tests. Stata version 14 (StataCorp, College Station, TX, USA) was used for all statistical analyses.

\section{RESULTS}

\section{Patient characteristics}

We included 180 patients, of whom 157 (87\%) completed all the questionnaires: 73 of these patients (47\%) received HD, 19 (12\%) received $\mathrm{PD}$ and 65 (41\%) were predialytic. No patient had nocturnal hemodialysis. The characteristics of the patients are presented in Table 1.

\section{Medication complexity}

The overall MRCI was $22.8 \pm 7.7$, and approximated a normal distribution (Figure 1). The MRCI score was $24.7 \pm 7.9$ in HD patients, $23.3 \pm 6.4$ in PD patients and $20.5 \pm 7.3$ in predialytic patients. In univariate linear regression analysis, the mean MRCI was higher in the dialysis group (coefficient $=3.86,95 \%$ confidence interval $=1.47-6.25, \quad \mathrm{P}=0.002)$ than in predialytic patients. In multivariable linear regression analysis, only female sex, CCI and use of phosphate binders were significant determinants of the MRCI (Table 2).

\section{Medication adherence}

The median MMAS-8 score was 8.0 (range $=1.5-8.0$ ), and the score distribution was skewed with a long tail to the left (Figure 2). Totals of 27 (17\%), 44 (28\%), and 86 (55\%) patients exhibited low, moderate and high adherence with medication, respectively, which means that $130(83 \%)$ of the participants had moderate/high adherence (MMAS-8 score $\geq 6$ ). The proportions of patients with moderate/high adherence were $78 \%, 100 \%$, and $83 \%$ among the HD, PD, and predialytic patients, respectively. In multivariable ordinal logistic regression analysis, the odds of being adherent seemed to decrease with a higher education level and with an increasing number of comorbidities; however, none of the explanatory variables showed a statistically significant association with medication adherence (Table 3). Furthermore, there was no association between medication adherence and dialysis vintage (data not shown).

\section{DISCUSSION}

This study found that female sex, comorbidities as assessed with the CCI and the use of phosphate binders were associated with a more-complex medication regimen, as indicated by a higher MRCI. In contrast, medication complexity and age were not associated with selfreported medication adherence as assessed with the MMAS-8.

\section{Medication complexity}

Overall, the present MRCIs are comparable with those reported for patients with other chronic diseases such as diabetes mellitus, heart failure and chronic obstructive pulmonary disease. ${ }^{31-33}$ The MRCIs for the present HD patients were lower than those in two previous studies involving HD patients who were considerably younger, having mean ages of 68 years and 54 years. ${ }^{11-13}$ Some differences in MRCIs might be attributable to differences in the interpretation of the "dialysate" item in section A of the MRCI, since it is not clearly defined. Another possible explanation is that younger patients adhere less to prescribed pharmacological treatments and therefore accumulate more prescribed medications. ${ }^{14,17,34}$

The present study found that being female was associated with higher complexity of medication regimens after adjustment for other variables, which supports previous findings. ${ }^{24,35-37}$ This may be related to a sex difference in the concern about one's own health or in the presenting of symptoms, which might influence the prescribing and diagnoses performed by physicians. ${ }^{38}$ Furthermore, the association of comorbidities such as cardiovascular disease with medication complexity found in the present study is also in accordance with previous studies. ${ }^{31,35}$

The finding of an association between phosphate binders and medication complexity is consistent with a previous study. ${ }^{7}$ This association is especially notable given that phosphate binders play an essential role in the treatment of CKD and account for up to half of the pill burden experienced by these patients. Phosphate binders typically come with additional instructions such as a requirement to take them with food, which adds to the complexity associated with both pills and their instructions that is captured by the MRCI.

In the present study of elderly patients, medication complexity was not associated with age or treatment 
Table 1 Characteristics of the study population according to adherence $(n=157)$

\begin{tabular}{|c|c|c|c|c|c|c|c|c|}
\hline \multirow[b]{3}{*}{ Age, years } & & & \multicolumn{6}{|c|}{ Adherence } \\
\hline & \multicolumn{2}{|c|}{ All $(n=157)$} & \multicolumn{2}{|c|}{ Low $(n=27)$} & \multicolumn{2}{|c|}{ Moderate $(n=44)$} & \multicolumn{2}{|c|}{ High $(n=86)$} \\
\hline & 76 & $(7.2)$ & 74 & $(5.2)$ & 76 & $(8.1)$ & 76 & $(7.2)$ \\
\hline Female & 42 & (27) & 6 & $(22)$ & 15 & $(34)$ & 21 & $(24)$ \\
\hline Married, or living with partner & 102 & $(65)$ & 18 & $(67)$ & 25 & $(57)$ & 59 & (69) \\
\hline Education, $\geq 12$ years & 39 & (25) & 12 & (44) & 9 & $(20)$ & 18 & (21) \\
\hline Body mass index, $\mathrm{kg} / \mathrm{m}^{2}$ & 25 & $(3.9)$ & 25 & $(2.8)$ & 24 & $(3.9)$ & 26 & $(4.1)$ \\
\hline \multicolumn{9}{|l|}{ MMSE-NR score ${ }^{a}$} \\
\hline $23-27$ & 39 & $(25)$ & 5 & (19) & 14 & $(32)$ & 20 & $(23)$ \\
\hline $28-30$ & 118 & (75) & 22 & (81) & 30 & (68) & 66 & $(77)$ \\
\hline \multicolumn{9}{|l|}{ Comorbidities } \\
\hline Hypertension & 124 & $(79)$ & 21 & $(78)$ & 35 & $(80)$ & 68 & $(79)$ \\
\hline Coronary disease & 61 & (39) & 14 & $(52)$ & 16 & $(36)$ & 31 & (36) \\
\hline Malignancy & 53 & (34) & 8 & (30) & 16 & (36) & 29 & (34) \\
\hline Diabetes mellitus & 42 & $(27)$ & 8 & $(30)$ & 12 & $(27)$ & 22 & (26) \\
\hline Peripheral vascular disease & 38 & (24) & 10 & (38) & 13 & (30) & 15 & (17) \\
\hline Cerebrovascular disease & 15 & (10) & 3 & (11) & 4 & (9) & 8 & (9) \\
\hline Chronic obstructive pulmonary disease & 12 & (8) & 1 & (4) & 4 & (9) & 7 & (8) \\
\hline \multicolumn{9}{|l|}{ Charlson Comorbidity Index } \\
\hline 2 or 3 & 52 & (33) & 6 & $(22)$ & 13 & $(30)$ & 33 & $(38)$ \\
\hline 4 or 5 & 82 & $(52)$ & 16 & (59) & 23 & $(52)$ & 43 & $(50)$ \\
\hline$>5$ & 23 & (15) & 5 & (19) & 8 & (18) & 10 & (12) \\
\hline \multicolumn{9}{|l|}{ Etiology of renal failure } \\
\hline Nephrosclerosis & 72 & $(46)$ & 12 & $(44)$ & 19 & $(43)$ & 41 & $(48)$ \\
\hline Diabetic nephropathy & 15 & (10) & 3 & (11) & 4 & (9) & 8 & (9) \\
\hline Glomerulonephritis & 14 & (9) & 1 & (4) & 4 & (9) & 9 & (10) \\
\hline Renal cancer & 9 & (6) & 3 & (11) & 5 & (11) & 1 & (1) \\
\hline $\mathrm{ADPKD}^{b}$ & 9 & (6) & 2 & $(7)$ & 2 & $(5)$ & 5 & $(6)$ \\
\hline Graft loss & 7 & (4) & 2 & (7) & & & 5 & (6) \\
\hline Interstitial nephritis & 5 & (3) & & & 1 & $(2)$ & 4 & (5) \\
\hline Post-renal complications & 5 & (3) & 2 & $(7)$ & 1 & (2) & 2 & $(2)$ \\
\hline Myeloma cast nephropathy & 5 & (3) & & & 2 & (5) & 3 & (3) \\
\hline Other causes ${ }^{c}$ & 8 & $(5)$ & & & 3 & $(7)$ & 4 & $(5)$ \\
\hline Unknown & 8 & (5) & 1 & (4) & 3 & (7) & 4 & (5) \\
\hline \multicolumn{9}{|l|}{ Treatment } \\
\hline Hemodialysis & 73 & $(46)$ & 16 & $(59)$ & 21 & $(48)$ & 36 & $(42)$ \\
\hline Peritoneal dialysis & 19 & (12) & 0 & & 5 & (11) & 14 & (16) \\
\hline Predialytic, $\mathrm{CKD}^{d}$ stage 5 & 65 & $(41)$ & 11 & $(41)$ & 18 & $(41)$ & 36 & $(42)$ \\
\hline \multicolumn{9}{|l|}{ Medications } \\
\hline Overall number of medications & 11 & [4-19] & 12 & {$[6-19]$} & 11 & {$[5-19]$} & 10 & [4-18] \\
\hline Number of pills taken daily & 16 & [3-45] & 18 & {$[7-45]$} & 15 & {$[3-28]$} & 14 & {$[5-33]$} \\
\hline \multicolumn{9}{|l|}{ Phosphate binders, $\mathrm{g}$} \\
\hline 0 & 50 & $(32)$ & 8 & $(27)$ & 12 & $(27)$ & 30 & $(35)$ \\
\hline $0.35-2.1$ & 27 & (17) & 4 & (15) & 8 & (18) & 15 & (17) \\
\hline $2.2-2.4$ & 27 & (17) & 2 & (7) & 11 & $(25)$ & 14 & (16) \\
\hline $2.5-4.9$ & 30 & (19) & 6 & $(22)$ & 8 & (18) & 16 & (19) \\
\hline $5.0-10.7$ & 23 & (15) & 7 & $(26)$ & 5 & (11) & 11 & (13) \\
\hline \multicolumn{9}{|l|}{ Medication administration } \\
\hline No external support & 65 & $(41)$ & 14 & $(52)$ & 18 & $(41)$ & 33 & $(38)$ \\
\hline Support from a home-attending nurse & 4 & (3) & 1 & (4) & 1 & $(2)$ & 2 & (2) \\
\hline Prepacked by pharmacy (multidose package) & 22 & (14) & 2 & (7) & 7 & (16) & 13 & (15) \\
\hline Weekly pill box & 65 & $(41)$ & 10 & (37) & 18 & $(41)$ & 37 & (43) \\
\hline
\end{tabular}

Data are mean $\pm \mathrm{SD}$, median [range] or number (\%) values.

${ }^{a}$ MMSE-NR = Mini Mental State Examination-Norwegian Revision.

${ }^{b} \mathrm{ADPKD}=$ autosomal dominant polycystic kidney disease.

${ }^{c}$ Other causes: amyloidosis, diffuse cutaneous systemic sclerosis, neurogenic cause, nephrectomy, and thin-membrane nephropathy.

${ }^{d} \mathrm{CKD}=$ chronic kidney disease. 


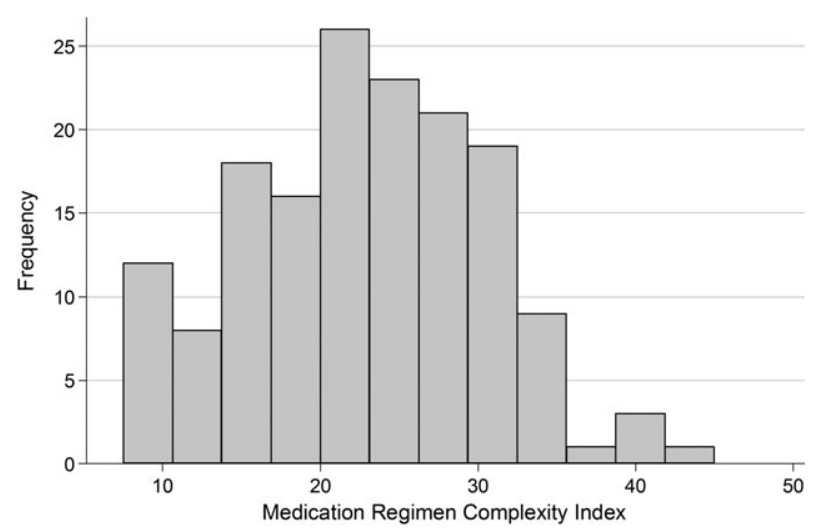

Figure 1 Medication Regimen Complexity Index for the study population $(n=157)$.

modality. Previous studies of the association between age and the MRCI have shown inconsistent results. $6,39,40$

\section{Medication adherence}

The high rate of medication adherence among the elderly patients with CKD included in this study was in agreement with the findings of several previous studies of medication adherence in $\mathrm{CKD}, \mathrm{HD}$, and $\mathrm{PD}$ populations, including one that also used the MMAS-8. ${ }^{16,18,41}$ In contrast, the adherence rate as assessed with the MMAS- 8 was previously found to be low for younger HD patients. ${ }^{17}$

The present study found no association between medication complexity and medication adherence, in line with one previous study but in contrast to most other

Table 2 Results of the multivariable linear regression analysis with the Medication Regimen Complexity Index (MRCI) as the dependent variable

\begin{tabular}{lrll}
\hline & Coef. $^{a}$ & \multicolumn{1}{c}{$95 \% \mathrm{CI}^{b}$} & $\mathrm{P}$ \\
\hline Age, years & 0.01 & $(-0.14$ to 0.15$)$ & 0.92 \\
Female vs. male & 2.44 & $(-0.07$ to 4.81$)$ & 0.044 \\
Treatment, dialysis & 0.73 & $(1.47$ to 2.92$)$ & 0.51 \\
$\quad$ vs. predialytic & & & \\
Charlson Comorbidity & & & \\
$\quad$ Index & & & \\
$\quad$ 4 or 5 vs. 2 or 3 & 2.56 & $(0.27$ to 4.85$)$ & 0.029 \\
$\quad$ 5 vs. 2 or 3 & 1.75 & $(-1.43$ to 4.93$)$ & 0.28 \\
Phosphate binders, g & & & \\
$\quad$ 0.35-2.1 vs. 0 & 7.57 & $(4.48$ to 10.66$)$ & $<0.001$ \\
2.2-2.4 vs. 0 & 3.18 & $(0.15$ to 6.21$)$ & 0.04 \\
$2.5-4.9$ vs. 0 & 7.48 & $(4.47$ to 10.48$)$ & $<0.001$ \\
25.0 vs. 0 & 11.21 & $(7.91$ to 14.52$)$ & 0.013 \\
\hline
\end{tabular}

${ }^{a}$ Coef. $=$ unstandardized beta coefficient.

${ }^{b} \mathrm{CI}=$ confidence interval.

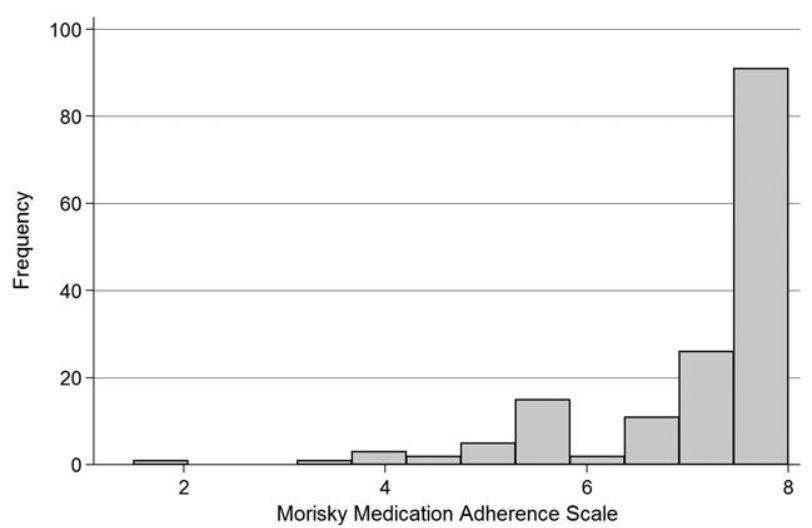

Figure 2 Morisky Medication Adherence Scale scores for the study population $(n=157)$.

studies. $^{9-11,42}$ However, the results of these studies are difficult to compare due to interstudy differences in populations, definitions of medication complexity, and definitions of medication adherence.

Increasing age has been associated with improved medication adherence in several studies, but this was not the case among the elderly population included in the present study. ${ }^{12,14,16,18}$ This difference may be attributed to the small variation in the ages of the subjects, although a previous study did find a difference in adherence between groups comprising subjects with mean ages of 78 and 66 years. $^{43}$

Table 3 Results of the multivariable ordinal logistic regression analysis with categories of medication adherence as the dependent variable $(n=157)$

\begin{tabular}{lccc}
\hline & $\begin{array}{c}\text { Odds } \\
\text { ratio }\end{array}$ & $95 \%$ CI & P \\
\hline Age, years & 1.00 & $(0.96-1.05)$ & 0.93 \\
Education, $\geq 12$ years & 0.48 & $(0.23-1.04)$ & 0.063 \\
Treatment, dialysis & 1.20 & $(0.58-2.45)$ & 0.63 \\
$\quad$ vs. predialytic & & & \\
Charlson Comorbidity Index & & & \\
$\quad$ 4 or 5 vs. 2 or 3 & 0.49 & $(0.22-1.08)$ & 0.077 \\
$\quad$ 5 vs. 2 or 3 & 0.40 & $(0.14-1.13)$ & 0.083 \\
Phosphate binders, g & & & \\
$\quad$ 0.35-2.1 vs. 0 & 0.79 & $(0.27-2.34)$ & 0.67 \\
$\quad$ 2.2-2.4 vs. 0 & 0.90 & $(0.33-2.44)$ & 0.84 \\
$\quad$ 2.5-4.9 vs. 0 & 0.65 & $(0.23-1.89)$ & 0.43 \\
$\quad$ 5 vs. 0 & 0.33 & $(0.10-1.11)$ & 0.073 \\
Medication Regimen & 1.03 & $(1.00-1.08)$ & 0.27 \\
$\quad$ Complexity Index & & & \\
Medication administration & 0.63 & $(0.31-1.28)$ & 0.20 \\
$\quad$ support, yes vs. no & & & \\
\hline
\end{tabular}


The present study found no association between increased use of phosphate binders and medication adherence, in contrast to previous reports of a negative association. ${ }^{3,44}$ However, we observed that there seemed to be a gradient in the odds ratios, with the probability of having high adherence lowering with an increasing intake of phosphate binders. The relationship between medication adherence and prescriptions may be bidirectional. For example, low medication adherence may lead to lack of effect, which may encourage physicians to provide more prescriptions. In contrast, the non-adherence of patients may increase when the number of prescriptions increases. Patients will obviously have some understanding of their diseases and treatments, not only based on objective clinical measurements but also influenced by their beliefs and attitudes. ${ }^{45,46}$

A higher education level or an increasing number of comorbidities was not associated with medication adherence in the present study. Some previous studies have highlighted a low education level as a predictor of non-adherence, in complete contrast with another study finding a higher education level to be associated with medication non-adherence. ${ }^{17,44,47}$ The lack of an association in our study may be related to the smallness of the sample, or it might be simply attributable to chance.

The complexity of medication regimens in patients with CKD identified by using tools such as the MRCI may increase the awareness of complex regimens and lead to a comprehensive medication review. Such a review could be useful for discussions involving multidisciplinary teams or patients about the personalization of medication and prescriptions.

\section{Strengths and limitations}

This was a multicentre study of elderly patients with advanced CKD that was conducted using standardized and validated tools. Each participant was asked about their medication use, in addition to using objective data from their medical and prescription records. The MRCI has previously been validated in a population with chronic obstructive pulmonary disease. The MMAS-8 has been validated in patients with hypertension, and has been used worldwide in other clinical illnesses. ${ }^{48}$ This is a self-reported questionnaire, and its use is consistent with guidelines of the National Institute for Health and Clinical Excellence that support using self-reported questionnaires to assess adherence in clinical practice. ${ }^{49}$

The present study was subject to some limitations that should be considered when interpreting its findings. Including only elderly subjects resulted in a relatively small sample that consequently led to limitations in the choice of variables and the power of the statistical analyses. Furthermore, the tools used to assess medication complexity and medication adherence were not primarily developed for a population with advanced CKD. There is no established optimal cut-off for the MRCI for defining high and low medication complexity in CKD populations, which would restrict the usefulness of the instrument in clinical practice. We assessed medication adherence using a self-reported questionnaire, which might have overestimated the adherence rate. We did not validate medication adherence with biochemical measurements, since this would have been difficult due to the large variations in the prescribed medications taken by patients with CKD. Furthermore, pill counts or the use of medication event monitoring systems were not feasible in this population. The MMAS-8 score cut-off between adherence and nonadherence was initially developed and validated among patients with hypertension, and there are no available data on what represents an appropriate cut-off in populations with CKD. ${ }^{26}$

This limited sample size of the study constrained the number of independent variables that could be included. Therefore, the study did not assess the association with nonadherence of some other potentially important variables, such as anxiety, depression, socioeconomic status or financial resources. ${ }^{50-53}$ Furthermore, we did not investigate the impact of provider-level variables. For example, the physician-patient relationship may constitute a barrier to medication adherence due to lack of time, trust or continuously changing attending physicians. ${ }^{52,54}$ Finally, this study had a cross-sectional design and did not investigate associations of medication complexity or medication adherence with unplanned hospitalizations or adverse side effects, or address changes in the MRCI over time.

In clinical practice, the issues may be more complicated, as nonadherence remains largely undisclosed. ${ }^{55,56}$ It is possible that general measures such as encouraging a good physician-patient relationship and focusing on medication appropriateness and side effects, as well as awareness of psychosocial challenges, may be important to reveal and address nonadherence, although we have no data to support this. ${ }^{56,57}$

In future studies of medication adherence in this group, the inclusion of qualitative aspects, such as the patients' perceptions of personal needs for medication and medication changes, experience of treatment or attitude toward shared decision-making, may be useful to help interpreting findings and understand patients' choices. This was, however, beyond the scope of the present study. 


\section{Conclusion}

This cross-sectional study found that female sex, comorbidity, and use of phosphate binders are associated with the complexity of medication regimens in elderly patients with advanced CKD. The medication adherence was generally high in the included population, and we found no clear association between medication complexity and self-reported medication adherence.

\section{ACKNOWLEDGMENT}

We thank the physicians and nurses at the dialysis centers and nephrology departments for supporting this work.

Manuscript received September 2018; revised January 2019; accepted January 2019.

\section{REFERENCES}

1 Tonelli M, Riella M. Chronic kidney disease and the aging population. Am J Hypertens. 2014;27:287-290.

2 Lindeman RD, Tobin J, Shock NW. Longitudinal studies on the rate of decline in renal function with age. J Am Geriatr Soc. 1985;33:278-285.

3 Chiu YW, Teitelbaum I, Misra M, de Leon EM, Adzize T, Mehrotra R. Pill burden, adherence, hyperphosphatemia, and quality of life in maintenance dialysis patients. Clin J Am Soc Nephrol. 2009;4:1089-1096.

4 St Peter WL. Improving medication safety in chronic kidney disease patients on dialysis through medication reconciliation. Adv Chronic Kidney Dis. 2010;17:413-419.

5 Yang P, Chen N, Wang R-R, Li L, Jiang S-P. Inappropriateness of medication prescriptions about chronic kidney disease patients without dialysis therapy in a Chinese tertiary teaching hospital. Ther Clin Risk Manag. 2016;12:1517-1524.

6 George J, Phun YT, Bailey MJ, Kong DC, Stewart K. Development and validation of the medication regimen complexity index. Ann Pharmacother. 2004;38:1369-1376.

7 Cummings KM, Becker MH, Kirscht JP, Levin NW. Psychosocial factors affecting adherence to medical regiments in a group of hemodialysis patients. Med Care. 1982;20:567-580.

8 Alves-Conceição V, Rocha KS, Silva FV, Silva RO, Silva DT, Lyra-Jr DP. Medication regimen complexity measured by MRCI: A systematic review to identify health outcomes. Ann Pharmacother. 2018;52:1117-1134.

9 de Vries ST, Keers JC, Visser R, et al. Medication beliefs, treatment complexity, and non-adherence to different drug classes in patients with type 2 diabetes. J Psychosom Res. 2014;76:134-138.

10 Ingersoll KS, Cohen J. The impact of medication regimen factors on adherence to chronic treatment: A review of literature. J Behav Med. 2008;31:213-224.
11 Neri L, Martini A, Andreucci VE, Gallieni M, Rey LA, Brancaccio D. Regimen complexity and prescription adherence in dialysis patients. Am J Nephrol. 2011;34: 71-76.

12 Ghimire S, Peterson GM, Castelino RL, Jose MD, Zaidi ST. Medication regimen complexity and adherence in Haemodialysis patients: An exploratory study. Am J Nephrol. 2016;43:318-324.

13 Cardone KE, Manley HJ, Grabe DW, Meola S, Hoy CD, Bailie GR. Quantifying home medication regimen changes and quality of life in patients receiving nocturnal home hemodialysis. Hemodial Int. 2011;15:234-242.

14 Mellon L, Regan D, Curtis R. Factors influencing adherence among Irish haemodialysis patients. Patient Educ Couns. 2013;92:88-93.

15 Denhaerynck K, Manhaeve D, Dobbels F, Garzoni D, Nolte C, De Geest S. Prevalence and consequences of nonadherence to hemodialysis regimens. Am J Crit Care. 2007; 16:222-235. quiz 236.

16 Griva K, Lai AY, Lim HA, Yu Z, Foo MW, Newman SP. Non-adherence in patients on peritoneal dialysis: A systematic review. PLoS One. 2014;9:e89001.

17 Alkatheri AM, Alyousif SM, Alshabanah N, et al. Medication adherence among adult patients on hemodialysis. Saudi J Kidney Dis Transpl. 2014;25:762-768.

18 Ghimire S, Castelino RL, Lioufas NM, Peterson GM, Zaidi ST. Nonadherence to medication therapy in Haemodialysis patients: A systematic review. PLoS One. 2015;10:e0144119.

19 Yu ZL, Lee VY, Kang AW, et al. Rates of intentional and unintentional nonadherence to peritoneal Dialysis regimes and associated factors. PLoS One. 2016;11: e0149784.

20 Akman B, Uyar M, Afsar B, Sezer S, Ozdemir FN, Haberal M. Adherence, depression and quality of life in patients on a renal transplantation waiting list. Transpl Int. 2007;20:682-687.

21 Charlson ME, Pompei P, Ales KL, MacKenzie CR. A new method of classifying prognostic comorbidity in longitudinal studies: Development and validation. J Chronic Dis. 1987:40:373-383.

22 Beddhu S, Bruns FJ, Saul M, Seddon P, Zeidel ML. A simple comorbidity scale predicts clinical outcomes and costs in dialysis patients. Am J Med. 2000;108:609-613.

23 Wimmer BC, Bell JS, Fastbom J, Wiese MD, Johnell K. Medication regimen complexity and number of medications as factors associated with unplanned hospitalizations in older people: A population-based cohort study. J Gerontol A Biol Sci Med Sci. 2016;71:831-837.

24 Ferreira JM, Galato D, Melo AC. Medication regimen complexity in adults and the elderly in a primary healthcare setting: Determination of high and low complexities. Pharm Pract (Granada). 2015;13:659.

25 Morisky DE, Ang A, Krousel-Wood M, Ward HJ. Predictive validity of a medication adherence measure in an 
outpatient setting. J Clin Hypertens (Greenwich). 2008; 10:348-354.

26 Morisky DE, Green LW, Levine DM. Concurrent and predictive validity of a self-reported measure of medication adherence. Med Care. 1986;24:67-74.

27 Morisky DE, DiMatteo MR. Improving the measurement of self-reported medication nonadherence: Response to authors. J Clin Epidemiol. 2011;64:255-257. discussion 258-263.

28 Berlowitz DR, Foy CG, Kazis LE, et al. Effect of intensive blood-pressure treatment on patient-reported outcomes. N Engl J Med. 2017;377:733-744.

29 Strobel C, Engedal K. MMSE-NR. Norsk Revidert Mini Mental Status Evaluering. Revidert og utvidet manual. Oslo: Nasjonalt Kompetansesenter for Aldring og Helse. 2008. https:// legeforeningen.no/geriatri.

30 Brant R. Assessing proportionality in the proportional odds model for ordinal logistic regression. Biometrics. 1990;46:1171-1178.

31 Negewo NA, Gibson PG, Wark PA, Simpson JL, McDonald VM. Treatment burden, clinical outcomes, and comorbidities in COPD: An examination of the utility of medication regimen complexity index in COPD. Int J Chron Obstruct Pulmon Dis. 2017;12:2929-2942.

32 Correr CJ, Melchiors AC, Fernandez-Llimos F, Pontarolo R. Effects of a pharmacotherapy follow-up in community pharmacies on type 2 diabetes patients in Brazil. Int J Clin Pharmacol. 2011;33:273-280.

33 Colavecchia AC, Putney DR, Johnson ML, Aparasu RR. Discharge medication complexity and 30-day heart failure readmissions. Res Social Adm Pharm. 2017;13: 857-863.

34 Karamanidou C, Clatworthy J, Weinman J, Horne R. A systematic review of the prevalence and determinants of nonadherence to phosphate binding medication in patients with end-stage renal disease. BMC Nephrol. 2008;9:2-2.

35 Rettig SM, Wood Y, Hirsch JD. Medication regimen complexity in patients with uncontrolled hypertension and/or diabetes. J Am Pharm Assoc (2003). 2013;53: 427-431.

36 Oosthuizen F, Dhoodhat E, Kazi S, et al. Assessing the complexity of medicine regimens a pilot study. Afr J Pharm Pharmacol. 2011;5:1863-1866.

37 Advinha AM, de Oliveira-Martins S, Mateus V, Pajote SG, Lopes MJ. Medication regimen complexity in institutionalized elderly people in an aging society. Int $J$ Clin Pharmacol. 2014;36:750-756.

38 van Wijk CM, van Vliet KP, Kolk AM. Gender perspectives and quality of care: Towards appropriate and adequate health care for women. Soc Sci Med. 1996;43: 707-720.

39 Wimmer BC, Johnell K, Fastbom J, Wiese MD, Bell JS. Factors associated with medication regimen complexity in older people: A cross-sectional population-based study. Eur J Clin Pharmacol. 2015;71:1099-1108.
40 Mansur N, Weiss A, Beloosesky Y. Looking beyond polypharmacy: Quantification of medication regimen complexity in the elderly. Am J Geriatr Pharmacother. 2012;10:223-229.

41 Sanchez-Gili M, Toro-Chico P, Perez-Encinas M, Gomez-Pedrero AM, Portoles-Perez JM. Pharmaceutical intervention on the therapeutic adherence in patients with chronic renal diseaseIntervención farmacéutica en la adherencia al tratamiento de pacientes con enfermedad renal crónica. Rev Calid Asist. 2011; 26:146-151.

42 Osterberg L, Blaschke T. Adherence to medication. N Engl J Med. 2005;353:487-497.

43 Park DC, Morrell RW, Frieske D, Kincaid D. Medication adherence behaviors in older adults: Effects of external cognitive supports. Psychol Aging. 1992;7:252-256.

44 Chan YM, Zalilah MS, Hii SZ. Determinants of compliance behaviours among patients undergoing hemodialysis in Malaysia. PLoS One. 2012;7:e41362.

45 Karamanidou C, Weinman J, Horne R. A qualitative study of treatment burden among haemodialysis recipients. J Health Psychol. 2014;19:556-569.

46 Kutner NG, Zhang R, McClellan WM, Cole SA. Psychosocial predictors of non-compliance in haemodialysis and peritoneal dialysis patients. Nephrol Dial Transplant. 2002;17:93-99.

47 Bouwman L, Eeltink CM, Visser O, Janssen J, Maaskant JM. Prevalence and associated factors of medication non-adherence in hematological-oncological patients in their home situation. BMC Cancer. 2017;17:739.

48 Moon SJ, Lee W-Y, Hwang JS, Hong YP, Morisky DE. Accuracy of a screening tool for medication adherence: A systematic review and meta-analysis of the Morisky medication adherence Scale-8. PLoS One. 2017;12: e0187139.

49 National Collaborating Centre for Primary C. National Institute for Health and Clinical Excellence: Guidance. Medicines Adherence: Involving Patients in Decisions About Prescribed Medicines and Supporting Adherence. London: Royal College of General Practitioners (UK) Royal College of General Practitioners. 2009.

50 Sundbom LT, Bingefors K. The influence of symptoms of anxiety and depression on medication nonadherence and its causes: A population based survey of prescription drug users in Sweden. Patient Prefer Adherence. 2013;7:805-811.

51 Goh ZS, Griva K. Anxiety and depression in patients with end-stage renal disease: Impact and management challenges - a narrative review. Int J Nephrol Renovasc Dis. 2018;11:93-102.

52 Briesacher BA, Gurwitz JH, Soumerai SB. Patients at-risk for cost-related medication nonadherence: A review of the literature. J Gen Intern Med. 2007;22:864-871.

53 Lau DT, Briesacher B, Mercaldo ND, et al. Older Patients' perceptions of medication importance and worth: An exploratory study. Drugs Aging. 2008;25:1061-1075. 
54 Mechta Nielsen T, Frøjk Juhl M, Feldt-Rasmussen B, Thomsen T. Adherence to medication in patients with chronic kidney disease: A systematic review of qualitative research. Clin Kidney J. 2018;11:513-527.

55 Balkrishnan R. Predictors of medication adherence in the elderly. Clin Ther. 1998;20:764-771.
56 Gellad WF, Grenard JL, Marcum ZA. A systematic review of barriers to medication adherence in the elderly: Looking beyond cost and regimen complexity. Am J Geriatr Pharmacother. 2011;9:11-23.

57 Ha JF, Longnecker N. Doctor-patient communication: A review. Ochsner J. 2010;10:38-43. 